\title{
Perinatal risk factors for necrotizing enterocolitis
}

\author{
V Y H YU, R JOSEPH, B BAJUK, A ORGILL, AND J ASTBURY \\ Department of Paediatrics, Queen Victoria Medical Centre, Melbourne, Australia
}

SUMmaRY The perinatal histories of 50 very low birthweight infants weighing $1500 \mathrm{~g}$, or less, with necrotizing enterocolitis were compared with those of the remaining 325 very low birthweight infants who were admitted to this hospital during a four year study period. Many factors previously reported to be associated with necrotizing enterocolitis were found with equal frequency in both groups of babies. The only adverse factor which was more frequently present in patients with necrotizing enterocolitis was hypothermia on admission to hospital. Those infants who developed severe necrotizing enterocolitis also had a higher incidence of polycythaemia. A further controlled study which examined feeding practices showed that the timing, type, and volume of milk feeding were not different in infants with necrotizing enterocolitis and matched controls. Prematurity is clearly the greatest risk factor which predisposes to the development of necrotizing enterocolitis and most of the factors previously implicated in the aetiology may simply represent the descriptive characteristics of a population of sick, very low birthweight infants.

The pathogenesis of necrotizing enterocolitis is not fully understood. It has been postulated that the disease results from hypoxaemia and mucosal injury aggravated by feeding and bacterial proliferation. Many perinatal events which were thought to predispose to necrotizing enterocolitis occurred as frequently, however, in matched control infants. ${ }^{1-6}$ In all these studies the investigators selected one to three infants of similar birthweight to serve as controls for each patient with necrotizing enterocolitis. Only two previous studies compared the incidence of risk factors among low birthweight infants who had necrotizing enterocolitis with the entire low birthweight population who did not have this. ${ }^{7 \times}$ They showed that very few, if any, obvious identifiable risk factors were consistently associated with the occurrence of this disease.

Necrotizing enterocolitis is associated with prematurity and has been shown to be especially common among very low birthweight $(1500 \mathrm{~g}$, or less) infants." It is therefore particularly important to identify pathogenic factors in this high risk group. We analysed and compared perinatal histories of 50 very low birthweight infants with necrotizing enterocolitis and those of the remaining 325 very low birthweight infants admitted to this hospital during the same four year period. Because feeding practices have been implicated in both the causation and prevention of necrotizing enterocolitis, these were examined in depth in infants before disease onset and were compared over an equivalent postnatal period with those in matched control infants.

\section{Patients and methods}

During the study period, January 1977 to December 1980 , 50 very low birthweight infants were diagnosed as having necrotizing enterocolitis (Table 1). The criteria used for diagnosis were similar to those in two previous studies. ${ }^{1011}$ Evidence of systemic illness included recurrent apnoea, lethargy, poor circulation, temperature instability, and metabolic acidosis. Signs attributable to gastrointestinal dysfunction included abdominal distension, blood in the stools, gastric residue, and diarrhoea. Thirty two infants whose abdominal radiographs showed gaseous distension, asymmetry of gas pattern and intramural gas in the form of a granular or foamy

Table 1 Incidence of necrotizing enterocolitis (NEC) in 375 infants of birthweight less than $1500 \mathrm{~g}$

\begin{tabular}{llll}
\hline Birthweight & $\begin{array}{l}\text { Infants with } \\
\text { mild NEC }\end{array}$ & $\begin{array}{l}\text { Infants with } \\
\text { severe NEC }\end{array}$ & $\begin{array}{c}\text { All infants } \\
\text { with NEC }\end{array}$ \\
\hline $\begin{array}{c}5(1) 1-1(0)(0) \\
(\mathrm{n}=1(17)\end{array}$ & $4(4 \%)$ & $11(10 \%)$ & $15(14 \%)$ \\
$\begin{array}{c}1(0) 1-150) \\
(\mathrm{n}=268)\end{array}$ & $14(5 \%)$ & $21(8 \%)$ & $35(1.3 \%)$ \\
$\begin{array}{c}\text { Total } \\
(\mathrm{n}=375)\end{array}$ & $18(5 \%)$ & $32(9 \%)$ & $50(1.3 \%)$ \\
\hline
\end{tabular}


pattern were considered to have mild necrotizing enterocolitis. Severe cases were defined as those whose radiographs showed a curvilinear intramural gas pattern, portal venous gas, or pneumoperitoneum. These severe radiological abnormalities were found in 18 of the 50 patients.

The birthweight of these 50 infants was mean

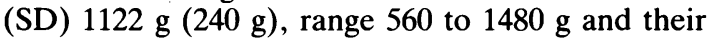
gestational age was mean (SD) 29 weeks (2 weeks), range 24 to 35 weeks. Seven $(14 \%)$ were small for gestational age. The age at diagnosis ranged from 1 day to 10 weeks but $80 \%$ of cases occurred within the first three weeks. No difference in the frequency of systemic or gastrointestinal signs and symptoms was observed between mild and severe cases. Eighty three per cent had haematological changes of sepsis and $38 \%$ had bacteria cultured from blood, stools, or peritoneal fluid - the most common being Clostridium perfrigens. Their medical and surgical management, short term outcome, and late morbidity at 2 years of age have been reported. ${ }^{12}$ Analysis of the monthly occurrence of necrotizing enterocolitis over the 48 month period is shown in the Figure.

Details of the total population of very low birthweight infants admitted during the four year period have been summarised in a previous study. ${ }^{13}$ The incidence of necrotizing enterocolitis was $13.3 \%$ in very low birthweight admissions-15 $(14.0 \%)$ of 107 infants who weighed 501 to $1000 \mathrm{~g}$ and $35(13.1 \%)$ of 268 infants who weighed 1001 to $1500 \mathrm{~g}$ developed the disease.

During the second half of the study period (1979 and 1980) there was a standard feeding regimen for very low birthweight infants; intermittent gavage milk feeding was begun early and supplemental parenteral nutrition before the establishment of full oral feeds became routine. With few exceptions milk feeding was started within the first week, usually at age 3 or 4 days, after the infant had passed meconium and was able to maintain blood gases and a stable $\mathrm{pH}$. Whenever possible fresh expressed breast milk from the infants' own mothers was used. This was stored, cooled, and given to the infants within 24 hours of collection. Pooled donor breast milk or milk that had been frozen or pasteurised was not used. Milk formula (Nan, Nestlés) was used whenever the supply of fresh breast milk ran out temporarily.

The feeding histories of infants with and without necrotizing enterocolitis were compared in a case control study for this two year period during which a standard feeding regimen was used. Thirteen of the 18 infants with severe disease were born during this period. Two control infants, admitted before and after each of the 13 patients and matched for a birthweight of $\pm 200 \mathrm{~g}$, were selected for comparison.

The results in this report were tabulated as the mean (SEM) or the number and percentage of infants with the specific factor. Statistical analysis was by $\chi^{2}$ and Student's $t$ tests.

\section{Results}

None of the obstetric and intrapartum factors listed in Table 2 or neonatal factors listed in Table 3 were found to be significantly more common in the 50 patients with necrotizing enterocolitis than in the

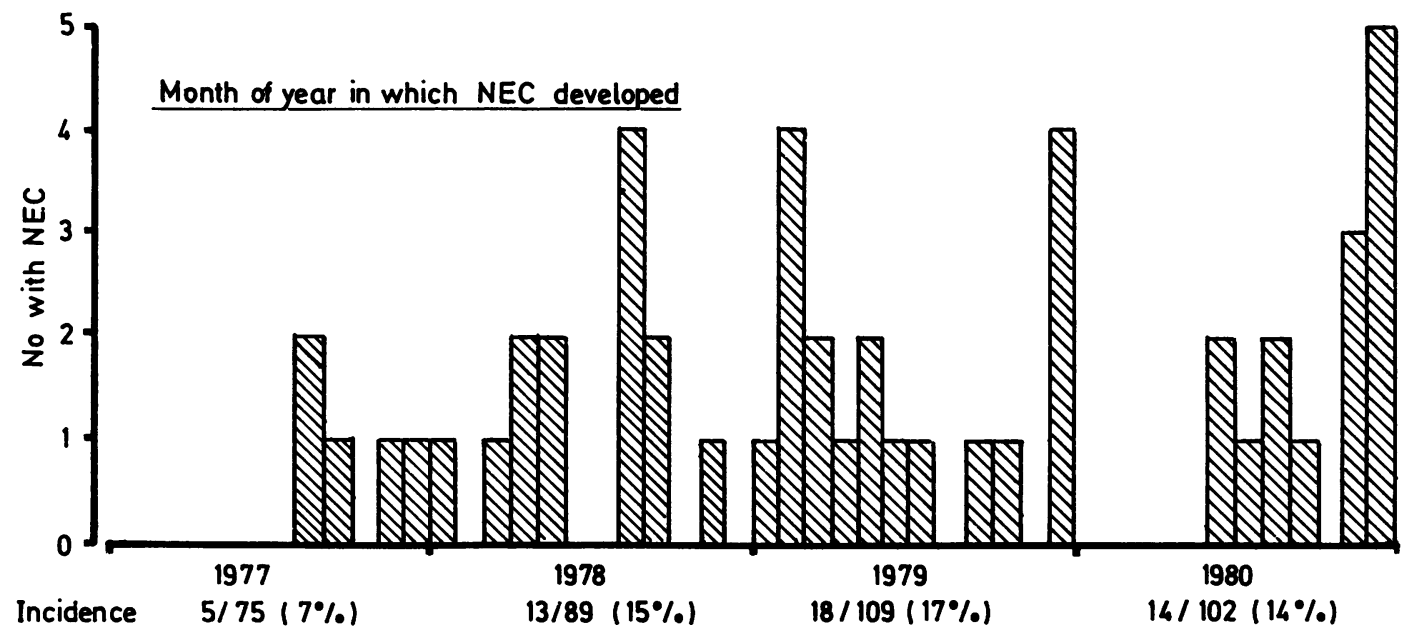

Figure Monthly occurrence of necrotizing enterocolitis (NEC) during the study period. 
Table 2 Obstetric and intrapartum factors in 50 infants with necrotizing enterocolitis (NEC) and in 325 infants without NEC, of birthweight less than $1500 \mathrm{~g}$

\begin{tabular}{|c|c|c|}
\hline & $\begin{array}{l}\text { Infants } \\
\text { with NEC }\end{array}$ & $\begin{array}{l}\text { Infants } \\
\text { without NEC }\end{array}$ \\
\hline \multicolumn{3}{|l|}{ Rupture of membranes longer } \\
\hline Amnionitis & $20(40 \%)$ & $101(31 \%)$ \\
\hline Caesarean section & $26(52 \%)$ & $124(38 \%)$ \\
\hline Birthweight (g). mean (SD) & $1122(34)$ & $1158(13)$ \\
\hline Gestational age (wks), mean (SD) & $29 \cdot 0(0 \cdot 3)$ & $29 \cdot 1(0 \cdot 1)$ \\
\hline Boys & $27(54 \%)$ & $159(49 \%)$ \\
\hline Small for gestational age & $7(14 \%)$ & $33(10 \%)$ \\
\hline \multicolumn{3}{|l|}{ Apgar score $0-3$} \\
\hline 1 minute & $17(34 \%)$ & $90(28 \%)$ \\
\hline 5 minutes & $2(4 \%)$ & $29(9 \%)$ \\
\hline \multicolumn{3}{|l|}{ Resuscitation at birth } \\
\hline Endotracheal intubation & $18(36 \%)$ & $108(33 \%)$ \\
\hline Bicarbonate therapy & $9(18 \%)$ & $82(25 \%)$ \\
\hline \multicolumn{3}{|l|}{ Data on admission } \\
\hline $\mathrm{pH}<7 \cdot 2^{\circ}$ & $14(29 \%)$ & $94(32 \%)$ \\
\hline Base deficit $>10 \mathrm{mmol} / \mathrm{I}^{\circ}$ & $4(8 \%)$ & $64(21 \%)$ \\
\hline Haematocrit $<40 \%{ }^{\dagger}$ & $6(12 \%)$ & $39(13 \%)$ \\
\hline Haematocrit $>60 \%$ & $6(12 \%)$ & $35(12 \%)$ \\
\hline Temperature $<35.5^{\circ} \mathrm{C}$ & $37(74 \%)$ & $10.3(32 \%)^{\frac{\hbar}{t}}$ \\
\hline
\end{tabular}

Data based on 48 infants with NEC and 298 without NEC.

${ }^{\dagger}$ Data based on 49 infants with NEC and 303 without NEC.

${ }^{+} \chi^{2}=33 \cdot 2 . \quad P<0 \cdot(0005$.

Table 3 Neonatal factors in 375 very low birthweight infants-50 with necrotizing enterocolitis (NEC) and 325 without NEC

\begin{tabular}{|c|c|c|}
\hline & $\begin{array}{l}\text { Infants } \\
\text { with NEC }\end{array}$ & $\begin{array}{l}\text { Infants } \\
\text { without NEC }\end{array}$ \\
\hline \multicolumn{3}{|l|}{ Respiratory distress } \\
\hline Absent & $10(20 \%)$ & $81(25 \%)$ \\
\hline Mild, moderate & $8(16 \%)$ & $29(9 \%)$ \\
\hline Severe & $32(64 \%)$ & $215(66 \%)$ \\
\hline Persistent pulmonary hypertension & $3(6 \%)$ & $41(13 \%)$ \\
\hline Pneumothorax & $4(8 \%)$ & $49(15 \%)$ \\
\hline Patent ductus arteriosus (PDA) & $20(40 \%)$ & $140(4.3 \%)$ \\
\hline Indomethacin therapy for PDA & $5(10 \%)$ & $46(14 \%)$ \\
\hline Lowest $\mathrm{pH}$ in first 4 days $\leqslant 7 \cdot(x)^{\circ}$ & $6(12 \%)$ & $37(12 \%)$ \\
\hline $\begin{array}{l}\text { Lowest } \overline{P O}_{2} \text { in first } 4 \text { days } \\
\leqslant 40 \mathrm{mmg}^{4}\end{array}$ & $17(34 \%)$ & $1.30(44 \%)$ \\
\hline $\begin{array}{l}\text { Umbilical arterial catheterisation } \\
\text { (UAC) }\end{array}$ & $39(78 \%)$ & $261(70 \%)$ \\
\hline $\begin{array}{l}\text { Peripheral circulatory changes from } \\
\text { UAC }\end{array}$ & $16(32 \%)$ & $85(23 \%)$ \\
\hline Exchange transfusion & $7(14 \%)$ & $30(9 \%)$ \\
\hline
\end{tabular}

Data based on 50 infants with NEC and 297 without NEC.

tData based on 48 infants with NEC and 289 without NEC.

remaining 325 very low birthweight infants except for hypothermia on hospital admission. Severe respiratory distress was defined in this study as the need for assisted ventilation. Hyaline membrane disease was the primary diagnosis in $24 \%$ of infants with necrotizing enterocolitis and $35 \%$ in the remainder. Apnoea of prematurity was the second most common diagnosis leading to assisted ventilation and occurred in $26 \%$ and $19 \%$ of the respective groups. Neither of these differences were found to be statistically significant.
Table 4 Data on milk feeding in 13 very low birthweight infants with severe necrotizing enterocolitis (NEC) and in 26 matched control infants

\begin{tabular}{lll}
\hline & NEC infants & Control infants \\
\hline $\begin{array}{l}\text { Timing of feed } \\
\text { Fed before diagnosis }\end{array}$ & $12(92 \%)$ & $25(96 \%)$ \\
Age at first feed (days). & $4 \cdot 3(1 \cdot 1)$ & $3 \cdot 2(0 \cdot 5)$ \\
$\begin{array}{l}\text { Type of feed } \\
\text { Breast milk only }\end{array}$ & $0(0 \%)$ & $0(0 \%)$ \\
$\begin{array}{l}\text { Formula only } \\
\text { Both types of feed }\end{array}$ & $3(23 \%)$ & $4(15 \%)$ \\
$\begin{array}{l}\text { Predominantly on formula } \\
\text { Volume of feed }\end{array}$ & $8(69 \%)$ & $21(81 \%)$ \\
$\begin{array}{l}\text { Day before diagnosis (ml/kg/day). } \\
\text { mean (SD) }\end{array}$ & $89(7)$ & $15(60 \%)$ \\
\hline
\end{tabular}

Eighteen of the 50 patients with necrotizing enterocolitis were considered to have severe disease based on radiological criteria as previously described. When the incidence of the same perinatal factors was analysed in these 18 infants with severe disease and compared with the remaining 357 infants, hypothermia on admission remained statistically more frequent in the former group. In addition, five $(28 \%)$ infants with severe disease had a central haematocrit value of over $60 \%$ on hospital admission compared with $36(10 \%)$ in the remaining infants $\left(\chi^{2}=3 \cdot 84, P=0.05\right)$.

In the case control study, data before the onset of the disease from each of the 13 infants with severe necrotizing enterocolitis born during the last two years of the study period were compared with data from an equivalent period of time on two control infants. The birthweights were mean (SEM) $1172 \mathrm{~g}$ $(75 \mathrm{~g})$ in the disease group and $1179 \mathrm{~g}(47 \mathrm{~g})$ in the control group, and gestational ages were mean (SEM) 29.2 weeks $(0.4$ weeks) and 28.9 weeks $(0.5$ weeks) respectively, confirming the biographical similarities of the two groups. Table 4 shows that none of the differences in timing, type, and volume of milk feeding between the two groups were statistically significant.

\section{Discussion}

The incidence of necrotizing enterocolitis in very low birthweight infants varied between $14 \%$ and $17 \%$ except for the first year of the study period. No seasonal pattern was evident, similar to the experience in larger infants. ${ }^{4}{ }^{14}$ For a disease which shows such erratic monthly variability, a long study period is required. Only one other controlled investigation has been undertaken over a similar period. ${ }^{8}$ The present series has the highest number of very low birthweight infants with necrotizing enterocolitis 
reported to date, and this was compared with a large control group from the entire very low birthweight population.

The observed peaks during the study may represent outbreaks of cases as has been described previously. ${ }^{14} 15$ This lends support to an infectious cause for necrotizing enterocolitis but specific pathogens were not isolated consistently from diseased infants during these peaks nor were differences found in endemic and epidemic cases, similar to the findings of a previous study. ${ }^{15}$ Overgrowth of organisms within the normal gut flora probably produces necrotizing enterocolitis in the immature gut but it remains uncertain which perinatal risk factors predispose to such invasive bacterial proliferation.

Past descriptive clinical reviews have listed associated perinatal complications which might have been interpreted as significant in pathogenesis. ${ }^{16}{ }^{17}$ Case control studies which included patients of all birthweights have challenged the concept that many of these perinatal events are aetiologically important and predispose infants to disease. ${ }^{1-6}$ Many infants admitted to neonatal intensive care units have perinatal asphyxia, respiratory distress, umbilical artery catheters etc and these factors may simply be coincidental findings in infants who later develop necrotizing enterocolitis. Although one case control study showed that perinatal asphyxia and the use of umbilical catheters were more common in patients with necrotizing enterocolitis than control infants, only five of the 17 patients in that study were of very low birthweight. ${ }^{2}$

To avoid the potentially biasing effects of selection criteria employed in obtaining, often retrospectively, a matched control group two previous studies described 21 and 48 necrotizing enterocolitis patients respectively and compared these with the remaining admissions during the study period. ${ }^{78} \mathrm{~A}$ moderately depressed Apgar score at one minute and hypertonic feeding were found more frequently in the patients with necrotizing enterocolitis in one study ${ }^{7}$ and abruptio placenta and severe respiratory distress in the other, ${ }^{8}$ out of a total of about 50 perinatal factors analysed. In the present study a body temperature on admission of less than $35.5^{\circ} \mathrm{C}$ was the only significant factor found. Only one previous, controlled investigation reported the incidence of hypothermia in their study group but it was not different to that in retrospectively matched control infants. ${ }^{1}$ Over half of the patients with necrotizing enterocolitis were over $1500 \mathrm{~g}$, however, and as most of their infants were born elsewhere their average age of admission was over 12 hours.

When patients diagnosed as having severe necrotizing enterocolitis on radiological criteria were selected for analysis a central haematocrit of over $60 \%$ on admission was also found to be significantly more common than in the remaining very low birthweight population. This observation was not associated with a higher number of small for gestational age infants among those with severe disease. Hyperviscosity with attendant intravascular sludging and bowel ischaemia has been shown to be present with a haematocrit exceeding $60 \% .{ }^{18}$ The association between necrotizing enterocolitis and polycythaemia has been noted in case reports ${ }^{19} 20$ and animal experiments have supported the hypothesis that polycythaemia plays a role in the development of the disease. ${ }^{21} 22 \mathrm{~A}$ previous case control study showed that a central haematocrit of over $60 \%$ was one of two significant risk factors identified in infants whose birthweight was over $2500 \mathrm{~g} .{ }^{6}$ The one controlled study in which the number of very low birthweight infants with necrotizing enterocolitis was comparable to that in our study did not contain data on polycythaemia. ${ }^{8}$

It has been suggested that infants who are fed too much $^{23}$ or too soon ${ }^{24}$ are at increased risk of developing necrotizing enterocolitis. These studies suffer from the fault of comparing non-concurrent alternative forms of treatment and either poor selection or lack of controls. The only prospective controlled trial comparing a rapid feeding rate schedule with a slower feeding rate schedule failed to show any trend toward a greater incidence in infants fed at the rapid feeding rate. ${ }^{25}$ The present study indicates that the timing and volume of milk feeds in very low birthweight infants with necrotizing enterocolitis were the same for controls. This finding is similar to that reported in case control studies which included patients of all birthweights. Nevertheless, our data show that the disease rarely developed in infants who had never been fed and therefore a possible association between feeding and necrotizing enterocolitis cannot be denied. In a previous, randomised, controlled clinical trial comprising 17 pairs of very low birthweight infants given either total parenteral nutrition or early milk feeding for the first two weeks of life, none of the infants in the former group but four in the latter group developed necrotizing enterocolitis. ${ }^{26}$ These data suggest that feeding is important in the aetiology but the nature of the feeding practice which predisposes the infant to disease is obscure. The lack of absolute protection breast milk gives against the development of necrotizing enterocolitis has been reported previously. ${ }^{27}{ }^{28}$ Refrigeration and storage may have an adverse effect on breast milk leukocyte function and this or other confounding circumstances may offset the immunoactive factors present. Further studies are required to determine the role of fresh 
breast milk in the prevention of necrotizing enterocolitis in these infants.

The present data raise further questions on the importance of perinatal factors purported to predispose a high risk infant to necrotizing enterocolitis. Prematurity is clearly the most important risk factor, but many of the factors previously implicated in the pathogenesis may simply represent the descriptive characteristics of a population of sick, very low birthweight infants. Since there are still no proved methods of preventing disease development in these infants, early diagnosis and prompt treatment remain important as means of reducing the morbidity and mortality associated with necrotizing enterocolitis.

\section{References}

1 Frantz ID, L'Heurcux P. Engel RR. Hunt CE. Necrotizing enterocolitis. J Pediatr 1975;86:259-63.

2 Bunton GL, Durbin GM, McIntosh N, Shaw DG, Taghizadeh A, Reynolds EOR, Rivers RPA, Urman G. Necrotizing enterocolitis: controlled study of 3 years' experience in a neonatal intensive care unit. Arch Dis Child 1977;52:772-7.

3 Guinan M. Schaberg D. Bruhn FW, Richardson CJ, Fox WW. Epidemic occurrence of neonatal necrotizing enterocolitis. Am J Dis Child 1979:133:594-7.

4 Stoll BJ, Kanto WP, Glass RI, Nahmias AJ, Brann AW. Epidemiology of necrotizing enterocolitis: a case control study. $J$ Pediatr 1980;96:477-51

5 Ryder RW, Shelton JD, Guinan ME. Committee on necrotizing enterocolitis. Necrotizing enterocolitis: a prosepctive multicenter investigation. Am J Epidemiol 1980;112:113-23.

- Wilson R, Portillo M. Schmidt E, Feldman RA, Kanto WP. Risk factors for necrotizing enterocolitis in infants wcighing more than 2000 grams at birth: a case-control study. Pediatrics 1983;71:19-22.

7 Yu VYH, Tudehope DI. Neonatal necrotizing enterocolitis: perinatal risk factors. Med J Aust 1977:1:688-93.

* Kliegman RM, Hack M, Jones P. Fararoff AA. Epidemiologic study of necrotizing enterocolitis among low-birth-weight infants. J Pediatr 1982:100:440-4.

9 Yu VYH. Tudehope DI. Gill GJ. Necrotizing enterocolitis: clinical aspects. Med J Aust 1977;1:685-8.

10 Herbst JJ, Books LS. Clinical characteristics of NEC. In: Brown EG. Sweet AY, eds. Neonatal necrotizing enterocolitis. New York: Grune and Stratton, 1980:25-39.

1 Bell MJ. Ternberg JL, Feigin Rd, et al. Neonatal necrotizing enterocolitis: therapeutic decisions based on clinical staging. Ann Surg 1978;187:1-7.
12 Yu VYH, Jospeh R, Bajuk B, Orgill A, Astbury J. Necrotizing enterocolitis in very low birthweight infants: a four-year study. Aust Paediatr $J$ (in press).

13 Yu VYH, Zhao SM, Bajuk B. Results of intensive care for 375 very low birthweight infants. Aust Paediatr J 1982;18:188-92.

it Book LS, Overall Jr, JC. Herbst JJ, Britt MR. Epstein B. Jung AL. Clustering of necrotising enterocolitis: interruption by infection-control measure. $N$ Engl J Med 1977:297:984-6.

15 British association for perinatal paediatrics and the public health laboratory service communicable disease surveillance centre. Surveillance of necrotizing enterocolitis, 1981-2. Br Med J 1983:287:824-6.

16 Santulli TV. Schullinger JN. Herid WC. et al. Acute necrotizing enterocolitis in infancy: a review of 64 cases. Pediatrics 1975;55:376-87.

17 Kliegman RM. Fanaroff AA. Neonatal necrotizing enterocolitis: a nine-year experience. Am J Dis (hild 1981;135:603-7.

1* Wirth FH, Goldberg KE, Lubchenco LO. Neonatal hyperviscosity. Pediatrics 1979:63:833-6.

19 Leake RD. Thanapoulos B, Neiberg R. Hyperviscosity syndrome associated with necrotizing enterocolitis. Am J Dis Child 1975:129:1192-4.

20) Hakanson DO. Oh W. Necrotizing enterocolitis and hyperviscosity in the newborn infant. J Pediatr 1977:90:458-61.

21 Harrison MW, Connell RS, Campbell JR, Webb MC. Microcirculatory changes in the gastrointestinal tract of the hypoxic puppy: electron microscope study. J Pediatr Surg 1975;10: $599-608$.

22 Tobboel D, van Nie GJ, Molenaar JC. The effects of temporary general hypoxia and local ischemia on the development of the intestine: an experimental study. J Pediatr Siurg 198();15:57-62.

23 Goldman HI. Feeding and necrotizing enterocolitis. Am J Dis Child 1980;134:553-5.

24 Eyal F, Sagi E, Arad I, Avital A. Necrotizing enterocolitis in the very low birthweight infant: expressed breast milk feeding compared with parenteral feeding. Arch Dis Child 1982:57: 274-76.

25 Book LS, Herbst JJ. Jung AL. Comparison of fast and slow feeding rate schedules to the development of necrotizing enterocolitis. J Pediatr 1976:89:463-6.

26 Yu VYH, James B, Henry P. MacMahon RA. Total parenteral nutrition in very low birthweight infants: a controlled trial. Arch Dis Child 1979;54:653-61.

27 Moriartey RR. Finer NN. Cox SF, Phillips JH, Theman A, Stewart AR, Ulan OA. Necrotizing enterocolitis and human milk. J Pediatr 1979;94:295-6.

${ }^{2 \times}$ Kliegman RM, Pittard WB, Fanaroff AA. Necrotizing enterocolitis in neonates fed human milk. J Pediatr 1979:95:450-3.

Correspondence to Dr V Y H Yu, Department of Paediatrics, Queen Victoria Medical Centre, 172 Lonsdale Street, Melbourne, Victoria, 3000, Australia.

Received 12 January 1984 